\title{
EL CISNE “NEGRO” AMBIENTAL: ENSEÑANZAS QUE NOS DEJA LA PANDEMIA (DESDE EL PUNTO DE VISTA AMBIENTAL)
}

\author{
NÉSTOR CAFFERATTA \\ Universidad de Buenos Aires \\ ncafferatta@csjn.gov.ar
}

Fecha de recepción: 14/07/2020 - Fecha de aceptación: 13/01/2021

RESUMEN: Para entender el presente y el futuro del Derecho ambiental, no puede prescindirse de la consideración de la crisis de la teoría filosófica cartesiana donde se modeló y se sustentó el derecho positivo moderno, caracterizada por un marcado acento antropocéntrico, y del avance actual hacia una visión cada día más ecocéntrica, que plantea una nueva interpretación de la relación del Hombre con la Naturaleza, rompiendo la hegemonía de la idea del dualismo ontológico, para comprender al ser humano como parte de la naturaleza que interactúa en un modo sistémico de interrelación permanente y dinámico con los demás seres vivos, conformando una cosmogénesis que comparte no solo su origen sino también su destino.

Palabras clave: ecocentrismo, antropocentrismo, derecho ambiental, pandemia.

ABSTRACT: In order to understand the present and future of Environmental Law, we cannot ignore the crisis in Cartesian philosophical theory from which modern Law was shaped, characterised by a strong anthropocentric approach, and the current shift towards an increasingly ecocentric perspective, which presents a new understanding of the Human-Nature relationship that breaks with ontological dualism, so that we can understand human beings as part of nature, interacting in a systemic mode of permanent and dynamic interrelations with other living beings, conforming a cosmogenesis with shared origin and Destiny

Keywords: ecocentrism, anthropocentrism, Environmental law, pandemic.

SUMARIO: I. CISNE "NEGRO" AMBIENTAL - II. LECCIONES DE LA PANDEMIA - III. LA PRIMERA EPIDEMIA GLOBAL- IV. VISIÓN ECOSISTÉMICA- V. EFECTO MARIPOSA- VI. POST PANDEMIA- VII. LA HUMANIDAD COMO SUJETO DE DERECHOVIII. LA DRAMÁTICA AUSENCIA DE SOLIDARIDAD- IX. LA ÉTICA AMBIENTAL- X. LA ENCÍCliCA LAUDATO SI- XI. EL DERECHO AMBIENTAL NO ES UN CONVIDADO DE PIEDRA- XII. LA LóGICA DE LA PRECAUCIÓN- XIII. COLOFÓN- XIV. REFERENCIAS BIBLIOGRÁFICAS. 


\section{CISNE "NEGRO" AMBIENTAL}

Ricardo LORENZETTI, juez de la Corte Suprema de Justicia de Argentina, señala en un artículo sobre "La salud humana y la salud de la naturaleza"1, que este trágico hecho (COVID 19) debería hacernos comprender que se han cometido varios errores.

"Uno de ellos fue negar que el deterioro de la naturaleza tiene su causa en la acción humana". "La acción humana desarrollada a partir de la revolución industrial ha generado un período, llamado "ANTROPOCENO", cuyo desarrollo ilimitado puso en tensión extrema a todo el planeta": "La naturaleza es un sistema en el cual todas las partes están conectadas entre sí y tiene un orden interno generado a partir de la interacción de sus propios elementos". Cada elemento, explica "cumple su función diferenciada", al mismo tiempo que existen "múltiples modos de transmisión de información". "La naturaleza estuvo sometida a una fuerte presión que motivó desequilibrios constantes".

Además, destaca la capacidad de la naturaleza de adaptación al cambio, y el deterioro provocado por explotación irracional de los recursos. "Ese equilibrio dinámico, permite absorber muchos cambios, pero cuando estas alteraciones son demasiado importantes, se pierde la capacidad de RESILIENCIA". Por ello, "la naturaleza pierde su capacidad de resistir". "Se acumulan tensiones que llevan a una crisis y a un nuevo equilibrio".

La frase más impactante de este excelente trabajo, reflexivo y profundo, es la que recogemos en el título: "El detonante es un "cisne negro" inesperado, para quienes no quisieron mirar la presión que se iba acumulando". Afirma en síntesis, que: "La pandemia es una "corrección sistémica" un "cisne negro" nacido de un desorden previo, de una ruptura de la frontera entre la alimentación humana y los mercados de vida silvestre".

Los límites del obrar humano, encuentran fronteras en la naturaleza. "En el origen de numerosas enfermedades está la ruptura de las fronteras que la naturaleza ha establecido". "Nuestra interfaz con la vida silvestre se ve afectada por los cambios en el uso de la tierra, la deforestación, el comercio de la vida silvestre, y muchas otras actividades que alteran la circulación normal del virus. Estos cambios aumentan las tasas de contacto entre los animales portadores de virus y los humanos"2

Finalmente, recuerda las enseñanzas del prestigioso NICHOLAS ROBINSON ${ }^{3}$ para "integrar mejor la comprensión de la salud humana y animal con la salud del medio ambiente" y actuar para restaurar y mantener ecosistemas saludables para evitar la liberación de enfermedades", para concluir que "la estrategia es sistémica, porque se trata de modificar aspectos que no están directamente relacionados con la pandemia pero tienen un efecto final en su explosión".

\footnotetext{
1 LORENZETTI, R., "La salud humana y la salud de la naturaleza", publicado el 26 de abril de 2020, en www.infobae.com. Este extraordinario jurista, ha publicado una serie de trabajos sobre la crisis sanitaria y de salud de la pandemia COVID 19, las que están publicadas en www.expoterra.com.ar: "El desafío moral de la pandemia", publicado el 20/03/2020. "Medidas ante la pandemia y el Estado de Derecho", publicado el 28/03/2020. "Pandemia: la salida del aislamiento y sus desafíos", publicado el 05/04/2020. Asimismo, véase LORENZETTI, P., "El Derecho Ambiental en tiempos de pandemia", nota del diario La Opinión, 10 de mayo de 2020. Asimismo, LORENZETTI, R. y LORENZETTI, P., Derecho Ambiental, Editorial Rubinzal, Buenos Aires, 2019.

2 ROBINSON, N. A. y WALZER, C., "How do we prevent the next Outbreak", Scientific American, 25 de marzo de 2020, según la referencia de Ricardo Lorenzetti, en este mismo artículo.

${ }^{3}$ ROBINSON, N., "One World on Health, Legal preparations to avert a Pandemic", Westchester Lawyer, marzo 2020.
} 
Raúl BRAÑES ${ }^{4}$ definía el derecho ambiental como un conjunto de normas jurídicas que regulan las conductas humanas que pueden influir de una manera relevante en los procesos de interacción que tienen lugar entre los sistemas de los organismos vivos y sus sistemas de ambiente, mediante la generación de efectos de los que se esperan una modificación significativa de existencia de dichos organismos.

Viviendo esta pandemia COVID 19, quien fuera un alto funcionario del PNUMAORPALC, pensamos que tiene razón: el derecho ambiental busca armonizar, los "sistemas de los organismos vivos" con los "sistemas de ambiente". Dicho en otros términos, acotados, limitados o estrechos pero igualmente válidos, compatibilizar el sistema social con el sistema natural.

El hombre con la naturaleza.

Tal parece, que lo desmedido o desproporcionado, lo abusivo o excesivo, de la actividad antrópica está haciendo estragos en las leyes organizativas del sistema natural, y la pandemia COVID 19 no es sino, una de las consecuencias trágicas, que se desarrollaron a partir de los hechos precedentes.

El hombre, la sociedad global, de esta manera, ha dañado o afectado de manera significativa el sistema de contención natural, los límites o fronteras, que impedían el salto directo de los virus infecciosos de especies de la fauna silvestre, a los seres humanos.

O en otras palabras: El Mundo y la Tierra.

Consecuencia: lo que está en crisis es "el Mundo", los seres humanos que habitamos la Tierra.

Como respuesta (eco) a lo mal que nos relacionamos con la naturaleza, es esta emergencia sanitaria y de salud mundial, como si la naturaleza reaccionara en contra de ese ser "molesto" $\left(\mathrm{BOFF}^{5}\right)$ que somos los humanos, la Tierra o GAIA (LOVELOCK) se cansara, y se sacudiera para expulsar al hombre, y proseguir su existencia de manera más armónica y duradera.

No es una fantasía ni un delirio, es una realidad.

Aunque parece una pesadilla o un cuento de ciencia ficción, lo que hoy vivimos nos debe hacer reflexionar sobre muchas cosas que afectan al funcionamiento y la sustentabilidad de los ecosistemas, porque no sabemos todavía cómo vamos a salir de esta crisis, y tampoco sabemos, si esto no es la antesala de una crisis aún mayor.

Por lo pronto el 2020, es el año más largo de nuestras vidas: el que peor la pasamos en muchos aspectos. El año que lamentablemente o para el dolor de muchos, más vidas (muertes) o enfermedades graves produjo una epidemia de características extraordinaria.

\footnotetext{
${ }^{4}$ BRAÑES, R., "Tres décadas de evolución del derecho ambiental y su aplicación en América Latina", p. 94 en Primeras Jornadas Nacionales de Derecho Ambiental / 28 y 29 de Noviembre de 2001, Comisión Nacional del Medio Ambiente y Centro de Derecho Ambiental de la Facultad de Derecho de la Universidad de Chile; El desarrollo del derecho ambiental latinoamericano y su aplicación, PNUMA, 2001; Manual de Derecho Ambiental mexicano, FCE, México, 2004; "El Derecho para el Desarrollo Sostenible en la América Latina de nuestros días", Revista de Derecho Ambiental, publicación del Centro de Derecho Ambiental Facultad de Derecho Universidad de Chile, Año II, N. ${ }^{\circ}$ 2, 2006, p. 17; "El Derecho Ambiental en América Latina”, en GONZÁLEZ LAXE, F. (Aut.), Actas del IV Congreso Nacional de Derecho Ambiental, Aranzadi Thomson Reuters, Madrid, 2002, pp. 73-148.

${ }^{5}$ BOFF, L., Sustentabilidad. La urgencia ante el grito de la tierra, Editorial Santa María, Buenos Aires, 2017, p. 37.
} 
Algo estamos haciendo mal ${ }^{6}$.

\section{LECCIONES DE LA PANDEMIA}

Hay dos cuestiones que observamos como lecciones de esta pandemia: 1) la ausencia de respuestas globales, frente a problemas globales; 2) la relación de la pandemia con la problemática ambiental.

El manejo de la crisis del coronavirus a nivel global ha pecado de falta de sintonía entre los países. Tal es así, que no pudo disimular su sorpresa Antonio GUTERRES, Secretario General de Naciones Unidas, que llegó a afirmar, con franca desilusión que "el mundo no fue capaz de unirse y enfrentar la COVID-19 de forma coordinada".

Cuando el mundo ya ha superado los 3.300 .000 contagios confirmados y los 230.000, GUTERRES se confiesa impactado por el balance de la pandemia. "Es dramático ver toda la gente que está muriendo y es dramático ver el devastador impacto en economías y sociedades, especialmente sobre la gente más vulnerable"7.

El filósofo y jurista italiano, LUIGI FERRAJOLI, defiende una Constitución de la Tierra como la única manera realista de afrontar los problemas que, como las pandemias o el cambio climático, desbordan las fronteras. Los problemas globales no están en las agendas nacionales. Pero de su solución "depende la supervivencia de la humanidad". La pandemia "con su terrible balance diario de muertos", hace más visible y urgente la carencia de instituciones globales adecuadas. No obstante, expresa este notable filósofo y jurista italiano, exjuez, la esperanza que, "precisamente, esta emergencia del coronavirus provoque un despertar de la razón, generando la plena conciencia de nuestra fragilidad y de nuestra interdependencia global". "Por eso, hace más urgente y más compartida que cualquier otra catástrofe, la necesidad de un constitucionalismo planetario que colme semejante laguna, mediante la creación no tanto de instituciones de gobierno, que está bien que sigan confiadas sobre todo a los Estados, sino de funciones e instituciones globales de garantía de los derechos humanos".

Nos preguntamos entonces, si nuestra especialidad, el derecho ambiental, no es sino un derecho de supervivencia, de sobrevivencia, de la especie humana (la humanidad, el mundo) sobre el Planeta.

Creemos que la gran lección de esta pandemia, es que no se puede seguir destruyendo el Planeta, sin pagar un precio muy alto en términos de salud humana, por semejante inconducta, no se puede alterar el equilibrio ecológico de forma radical, porque tarde o temprano, ocurre lo peor: "se produce el salto (del virus) de la vida silvestre hacia las personas, la sociedad en su

\footnotetext{
${ }^{6}$ CAFFERATTA, N. A., PERETTI, E. y LORENZETTI, P., "El aporte del Derecho Ambiental a la lucha contra el Coronavirus (Covid-19)". Un trabajo conjunto en prensa para su edición, que forma parte de una magnífica obra colectiva que aborda la problemática de la pandemia y el derecho, bajo la dirección del notable civilista Ramón Daniel PIZARRO, Editorial Rubinzal, Buenos Aires.

7 BBC News, "Crisis del coronavirus | 'El mundo no fue capaz de unirse y enfrentar la covid-19 de forma coordinada": entrevista a Antonio Guterres, secretario general de Naciones Unidas', BBC News, 3 de mayo de 2020. Disponible en https://www.bbc.com/mundo/noticias-internacional-52509664

${ }^{8}$ GARCÍA JAÉN, B., "Entrevista a Luigi Ferrajoli, filósofo: 'Los países de la UE van cada uno por su lado defendiendo una soberanía insensata", El País, 28 de marzo de 2020. Disponible en https://elpais.com/ideas/202003-27/luigi-ferrajoli-filosofo-los-paises-de-la-ue-van-cada-uno-por-su-lado-defendiendo-una-soberaniainsensata.html
} 
conjunto, generando brotes y cobrándose millones de vidas humanas en todo el mundo"9. Como si se desatara la furia de la naturaleza contra la perturbación de los ecosistemas, dando lugar a una epidemia, en la que el ser humano se muestra frágil, carente de mecanismos de defensa adecuado, para poner límite a una verdadera pesadilla. Los temores que esta situación se prolongue, son cada vez mayores.

\section{LA PRIMERA EPIDEMIA GLOBAL}

Recientemente, publicamos con un alto magistrado de Corte provincial, Enrique PERETTI, un artículo sobre la pandemia ${ }^{10}$, donde recogíamos la opinión de un destacado médico epidemiólogo.

FRANK SNOWDEN ${ }^{11}$, el mayor experto sobre la historia de las epidemias, dice desde Roma, que "el coronavirus es la primera gran epidemia de la globalización" y agrega: "Las epidemias permiten entender la humanidad y la historia. Toca las fibras más íntimas de nuestra naturaleza humana". Asimismo, "nos plantean preguntas de vida o muerte y nuestra actitud hacia ambas. Nos preguntan sobre nuestras éticas. Nos muestran si nuestro mundo se preocupa por la gente más necesitada. Las epidemias son como mirarse en el espejo de la humanidad y puede decirle que no todo es bello. Tenemos un lado oscuro. Pero también un lado brillante, hay héroes en esta historia".

Este profesor de historia de la Medicina de la Universidad de Yale, médico graduado en la Universidad de Harvard y posgrado de la Universidad de Oxford, destaca algunas diferencias de esta pandemia.

"Primero, porque debemos comprender cómo comenzó, en un contexto de 8000 millones de personas, ciudades enormes, una deforestación que ejerce presión insostenible sobre los hábitats de los animales, que los lleva a trasladarse a otros lugares y a cruzarse con humanos, con los que nunca había interactuado antes. Así comenzó el Ébola, por ejemplo. Segundo, "debemos comprender cómo se transmite, que es por el aire, en un contexto de megaconcentración humana en centros urbanos, potenciando su propagación. Tercero, comprendamos cómo se expande, que es a través del transporte aéreo masivo, de modo que un virus que se desata en Yakarta por la mañana puede estar en Buenos Aires, Nueva York o Roma por la noche".

Por ello "el coronavirus no se puede entender sin la globalización, es un producto de esta era de la humanidad. Del mismo modo que la epidemia del cólera que asoló Europa y EUA durante el Siglo XIX fue posible porque era otra sociedad, distinta que la actual, con características en las que el cólera pudo avanzar, algo que hoy no sería posible en Nueva York o Roma, gracias a la revolución sanitaria posterior”. Concluye enfáticamente: ¡“Estamos lidiando con organismos vivos que requieren de ciertas condiciones para prosperar y somos nosotros quienes les damos estas condiciones!" Fuimos quienes generamos las condiciones para que el cólera se expandiera en su momento, también lo hicimos con el Ébola, creamos un nicho

\footnotetext{
9 EDITORIAL, "La destrucción del ecosistema y el origen del coronavirus", La Nación, 5 de abril de 2020. Disponible en https://www.lanacion.com.ar/editoriales/la-destruccion-del-ecosistema-y-el-origen-del-coronavirus$\underline{\text { nid2350879 }}$

${ }^{10}$ CAFFERATTA, N. y PERETTI, E., Pandemia de coronavirus. El dramático desafío global de la humanidad, en Rubinzal.

${ }^{11}$ ALCONADA MON, H., "Frank Snowden: 'Las epidemias son como mirarse al espejo de la humanidad, y puedo decir que no todo es bello", La Nación, 29 de marzo de 2020. Disponible en https://www.lanacion.com.ar/elmundo/frank-snowden-las-epidemias-son-como-mirarse-al-espejo-de-la-humanidad-y-puedo-decir-que-no-todo-esbello-nid2348455
} 
ecológico que permitió que el coronavirus fuera posible". Tuvimos suerte con el SARS, pero olvidamos la lección que nos estaba dando: fue apenas un ensayo de algo más grande que se estaba gestando. Y le recuerdo: no sabemos si algo aún más grande que el coronavirus se está gestando ahora". El profesor SNOWDEN predica la necesidad de aprender de las experiencias pasadas, corregir el rumbo, evitar los demonios de la mente humana. "Ahora no se trata de ir contra la globalización, que ya es un hecho, sino que se trata de cómo manejamos de un modo que nos beneficie y corregimos lo que debemos corregir, sólo así tendremos un futuro como humanidad. La definición de estupidez según Albert EINSTEIN, es seguir haciendo las mismas cosas y esperar un resultado distinto".

\section{VISIÓN ECOSISTÉMICA}

La óptica es sistémica (Lorenzetti).

Este criterio es el que adopta la Corte Suprema de Justicia de la Nación Argentina (CSJ), en materia ambiental.

Por ello, la visión del tribunal, en casos de afectación, contaminación o degradación ambiental de Cuencas hídricas, debe ser integral, holística y totalizadora. Por ello se dijo que la cuenca del río "es un sistema integral, que se refleja en la estrecha interdependencia entre las diversas partes del curso de agua" (F.340:1695) ${ }^{12}$.

El paradigma jurídico que ordena la regulación del agua es ECOCÉNTRICO, o SISTÉMICO, y no tiene en cuenta solamente los intereses privados o estaduales, sino los del mismo sistema, como bien lo establece la ley general del ambiente" (F.: 337:1361 y 340:1695) ${ }^{13}$. Finalmente, en otra causa relevante, se pone de resalto que LA REGULACIÓN JURÍDICA DEL AGUA HA PASADO DE UN MODELO ANTROPOCÉNTRICO, PURAMENTE DOMINIAL, A UN MODELO ECOCÉNTRICO SISTÉMICO ${ }^{14}$.

\section{EFECTO MARIPOSA}

Esto nos hace recordar el descubrimiento del meteorólogo estadounidense Edward Norton LORENZ (1930-2008) que con la frase "el aleteo de una mariposa en Brasil puede producir un tornado en Texas", que incluyó en una conferencia que pronunció el 29 de diciembre de 1972, en la AAAS (American Association for the Advancemente of Science), que luego se resumió como el "efecto mariposa", vale decir que pequeñas perturbaciones en el ambiente pueden producir cambios en proporciones enormes.

PNUMA (Programa de las Naciones Unidas para el Medio Ambiente) realizó una declaración sobre el contexto de la crisis sanitaria global solidarizándose con los miles de millones de personas en todo el mundo que sufren el impacto de la pandemia del COVID- 19. Para la organización, "es la mayor crisis desde la Segunda Guerra Mundial que enfrenta la

\footnotetext{
12 CSJ 1531/2017/CS1. Cuestión de Competencia. 22.08.2019. "FERNÁNDEZ, Miguel Ángel s/ infracción ley 24.051".

${ }^{13}$ CSJ 140/2011 (47-B)/ CS1.ORIGINARIO "BARRICK Exploraciones Argentinas S.A y otro c/ Estado Nacional s/ acción declarativa de inconstitucionalidad”. 04.07.2019. Fallos 342:917. CSJ 000714/2016/RH001 MAJUL, JULIO JESUS c/ MUNICIPALIDAD DE PUEBLO GENERAL BELGRANO Y OTROS s/ACCION DE AMPARO AMBIENTAL 11/07/2019.

${ }^{14}$ CSJ. La Pampa, Provincia de cl Mendoza, Provincia de s/ uso de aguas. CSJ 243/2014 (50-L) ICS1 ORIGINARIO (01/12/2017) Fallos: 340:1695.
} 
humanidad" y en ese sentido, sostiene que "la salud de las personas y la salud de nuestro planeta están íntimamente conectadas".

La actividad humana ha alterado prácticamente todos los rincones de nuestro planeta, desde la tierra hasta el océano. Y a medida que continuamos invadiendo implacablemente la naturaleza y degradando los ecosistemas, ponemos en peligro la salud humana. De hecho, "el $75 \%$ de todas las enfermedades infecciosas emergentes son zoonóticas, es decir, se transmiten de los animales a los humanos".

\section{POST PANDEMIA}

En este contexto posterior a la crisis, continúa el documento internacional de PNUMA, es necesario "reconstruir mejor", y "aprovechar las oportunidades para dar grandes pasos hacia inversiones verdes, como energía renovable, vivienda inteligente, contrataciones públicos ecológicas, o el transporte público, todo guiado por los principios y estándares de producción y consumo sostenibles".

En consonancia con esta recomendación, son resonantes las declaraciones de uno de los líderes de la política internacional, me refiero a la canciller alemana Angela MERKEL, quien en el importante "Congreso internacional del Diálogo de Petersberg", un congreso internacional anual sobre la lucha contra el calentamiento global, cuya actual edición es digital, instó a las naciones para que los programas de reconstrucción tras la crisis del coronavirus se lleven a cabo siguiendo criterios ambientales y climáticos, para combinar ecología y economía.

\section{LA HUMANIDAD COMO SUJETO DE DERECHO}

Otra cuestión que nos llama a reflexionar este problemática global (o mundial), que afecta a la humanidad en su conjunto, es el sujeto de derecho del derecho ambiental.

La humanidad está en peligro de extinción. El saldo negativo de esta pandemia se mide a diario por cantidad de muertos e infectados por la enfermedad, que presenta características derivadas de la gripe ${ }^{15}$. Se trata de una emergencia sanitaria y epidemiológica a escala mundial, que afecta a todos los países, naciones, estados del mundo, como nunca antes había ocurrido, aunque las anteriores epidemias, ébola y SARS, son antecedentes de esta última pandemia.

El 02/04/2020, la CIDH (Corte Interamericana de Derechos Humanos), dictó una novísima sentencia condenatoria de la Argentina, en un caso contencioso llevado por las Comunidades indígenas que se agrupan bajo la asociación Lhaka Honhat (Nuestra Tierra) por violación de los derechos de propiedad comunitaria, a la identidad cultural, el medio ambiente sano, a la alimentación adecuada y al agua de las comunidades originarias. Afirmó que el derecho a un medio sano constituye un interés universal y es un derecho fundamental para la existencia de la humanidad.

No es esta la primera vez que la CIDH califica al derecho ambiental de esta manera. Lo había hecho tres años antes, en la Opinión Consultiva O.C 23/17 a pedido de Colombia. Estas mismas ideas, fueron recogidas por la Corte Suprema de México, Sala $1^{\circ}$, el 14/11/2018, en el amparo promovido por la construcción del Parque Temático Ecológico de la laguna del Carpintero en la ciudad de Tampico, México, en defensa de un humedal (manglar), que es un

\footnotetext{
${ }^{15}$ El coronavirus es una pandemia de características letales, que amenaza la sociedad mundial, como un pesadilla que nos atormenta, provocando desolación y muerte a su paso. Nunca antes, la humanidad, se sintió tan afectada, con esta sensación de impotencia, debilidad, abandono, e inseguridad, en la que nos ha sumergido el coronavirus (COVID19).
} 
área especialmente protegida. Esta crisis sanitaria o epidemiológica, es una crisis de la humanidad en el Planeta.

Si no nos unimos, no colaboramos o cooperamos, en la búsqueda de solución de esta problemática común, es probable que los rebrotes de la infección, el contagio masivo, crónico, y grave, nos lleve a una crisis sanitaria y de salud, de efectos calamitosos.

\section{LA DRAMÁTICA AUSENCIA DE SOLIDARIDAD}

El profesor YUVAL NOAH HARARI ${ }^{16}$, señaló que la falta de solidaridad global y de liderazgo representa un peligro inmenso para la humanidad. El problema, dice este catedrático de la Universidad Hebrea de Jerusalén doctorado en Oxford, es que en estos tiempos del Covid19, "la falta de solidaridad global y liderazgo representa un peligro inmenso para la humanidad". Tanto es así que teme que afrontemos una "recesión global severa que nos golpeará a todos", aunque ciertos países ricos podrían salir adelante, mientras que otros en América Latina, Asia y África "podrían colapsar por completo", abriéndole paso a nuevos regímenes totalitarios. "Necesitamos un plan de salvataje económico global", alerta.

Aunque suene una obviedad, es importante el actuar solidario en crisis de este tipo ${ }^{17}$.

El necesario recurso a la "solidaridad", como fuente del derecho, es formulado por RAMÓN MARTÍN MATEO ${ }^{18}$, en una obra magnífica, que agrupa una serie de conferencias de este extraordinario maestro del derecho ambiental, bajo un título reflexivo e impactante: "El Hombre: una especie en peligro" 19 , a través de los cuales nos advierte, con claridad, que la supervivencia del "homo sapiens" "vendría amenazada", fundamentalmente, "por nuestra incapacidad para organizarnos socialmente y para actuar en forma solidaria con nuestros congéneres en el tiempo y en el espacio" ${ }^{20}$.

\footnotetext{
${ }^{16}$ ALCONADA MON, H., "Yuval Noah Harari: 'La falta de solidaridad global y de liderazgo representa un peligro inmenso para la humanidad", La Nación, 5 de abril de 2020. Disponible en https://www.lanacion.com.ar/elmundo/yuval-noah-harari-la-falta-de-solidaridad-global-y-de-liderazgo-representa-un-peligro-inmenso-para-lahumanidad-nid2350906

${ }^{17}$ Hemos estudiado esta cuestión antes que ahora, con el doctor Enrique Peretti, desde el punto de vista ambiental, en una obra bajo el título Los nuevos desafíos del derecho ambiental, con prólogo de Ricardo LORENZETTI, Rubinzal Culzoni Editores, de diciembre del 2019, donde proponemos el análisis de la evolución del derecho ambiental a escala global, partiendo de dos pilares fundantes: la solidaridad y la sustentabilidad.

${ }^{18}$ En este mismo libro, este extraordinario jurista español, expresa proféticamente que "podemos preguntarnos con pavor que sucedería si sucesivas mutaciones de este virus (se refería a los llamados, retro- virus, denominados así porque evolucionan hacia atrás, en un sentido inverso de la secuencia DNA- RNA), o la aparición de otros nuevos, a partir, por ejemplo del de la gripe, dieran lugar a la producción de parecidos o superiores estragos en la salud del hombre, transmitiéndose por inhalación a través del sistema respiratoria, si sigue desconociéndose la terapéutica adecuada. Una epidemia de estas características se llevaría por delante a nuestros congéneres".
}

${ }^{19}$ MARTÍN MATEO, R., El hombre: una especie en peligro, Campomanes S.L., 1993. Introducción, I. La previsible desaparición de la especie humana, pp. 19- 24, V. Las Ciencias Sociales y la Conservación de los Sistemas Ambientales, pp. 83- 107 en los que aborda además la temática de los derechos de la Tierra como derechos de la especie humana. En este libro, p. 23 expresa que "podemos preguntarnos con pavor que sucedería si sucesivas mutaciones de este virus (se refería a los llamados, retro- virus, denominados así porque evolucionan hacia atrás, en un sentido inverso de la secuencia DNA- RNA), o la aparición de otros nuevos, a partir, por ejemplo del de la gripe, dieran lugar a la producción de parecidos o superiores estragos en la salud del hombre, transmitiéndose por inhalación a través del sistema respiratoria, si sigue desconociéndose la terapéutica adecuada. Una epidemia de estas características se llevaría por delante a nuestros congéneres".

20 "Sólo por presunción y soberbia, comparable a las que ha hecho a nuestros semejantes manipular inconscientemente los sistemas naturales claves, se ha podido pensar que podemos aniquilar las condiciones de vida de nuestro actual habitáculo. Por destructiva que sean nuestras acciones, seremos felizmente incapaces de contrarrestar las enormes fuerzas que transmiten el testigo. Lo que sí está ciertamente en nuestras manos, es arruinar las condiciones físico- químicas de la biósfera que han permitido nuestra aparición y pervivencia en este minúsculo 
La clave está en que la sociedad debe cambiar su actitud frente a los problemas que nos afectan a todos, la solidaridad (Ramón Martín Mateo) y la empatía (Jeremy RIFKIN) juegan un papel descollante para salir de este atolladero.

\section{IX. ÉTICA AMBIENTAL}

La ética ambiental es una especie del género bioética ${ }^{21}$, entendida esta última en un sentido amplio, comprensivo no sólo de la ética clínica, sino también la ética social, global, y la ética que relaciona el ser humano con la sociedad (el otro), y con su entorno natural / cultural.

Un juez Pedro F. HOOFT, destaca que la bioética es "una reflexión moral sobre las implicaciones, los factores condicionantes, y el impacto de la investigación biomédica y psicosocial, todo ello en íntima relación con el bienestar humano, la preservación del medio ambiente y la justicia social" 22 .

La biotecnología (la biología molecular), los resultados de las aplicaciones primero en microorganismos, y luego, en la obtención de nuevos animales y plantas, en sus manifestaciones más modernas que dan lugar a organismos modificados genéticamente, las técnicas de incorporación del ADN y utilización de vectores, la incorporación directa de material genético, fusión celular, en seres vivos para conseguir productos y tecnologías útiles, constituyen instrumentos que sirven para la protección ambiental. Las nuevas tecnologías genéticas han abierto la posibilidad de descifrar el genoma humano, lo que implica una aceleración científica sin precedentes.

Por lo demás, muchas de las consecuencias y derivaciones de las prácticas médicas apoyadas en conocimientos genéticos suscitan sin duda importantes interrogantes éticos.

TOFFLER $^{23}$ declaró que "las tecnologías modernas avanzadas nos plantearán problemas éticos que ahora apenas vislumbramos: la manipulación genética, la posibilidad de acceder a la inmortalidad a través de la criogenización".

Ramón MARTÍN MATEO ${ }^{24}$ afirma que "es indudable que existe una difundida conciencia sobre la preceptividad de ciertas pautas de comportamiento en relación a la naturaleza, lo que debería inhibir la realización de actividades contrarias a ellas".

Recuerda que al despertar la percepción ético- ambiental de la Humanidad, contribuyeron también con pocos años de prelación, autores como GARRET, CARSON Y NICHOLSON". Pero la emergencia de la ética ambiental, "ha sido precedida por la consolidación de otros valores hoy ya positivizados". Así, "el progresivo afinamiento de la conciencia moral del hombre, ha determinado la consolidación de la ética ambiental, que mucho

espacio del Cosmos. Podemos efectivamente desaparecer, y sin duda lo haremos, si seguimos comportándonos irreflexivamente. Nos llevaremos delante a otros seres, como los primates, pero la vida seguirá tercamente y alcanzará seguramente cotas más altas a lo largo de la evolución de millones de años, que genialmente identificó Darwin a finales del pasado siglo. Nuestro recambio ya está en marcha y es probable que se realice a partir de especies con mayor capacidad comunitaria que la nuestra. Se atribuye a Einstein una observación en el sentido de que si las ratas que tienen esos atributos, hubieran alcanzado mayor tamaño, habría vencido y desplazado al hombre".

${ }^{21}$ HOOFT, P. F., Bioética, derechos humanos y sociedad civil. Conceptos introductorios, Capítulo I, en "Casos de bioética en la jurisprudencia", Temis, Bogotá, 2005, p. 3. Donde se habla de la bioética como un puente hacia el futuro y entre las dos culturas - la ciencia y las humanidades- como respuesta al desafío de la crisis bioética en la era tecnológica, importa dar un giro en la ética médica desde la posición tradicional, centrada en el médico y el paciente. Aquí entonces la referencia a la ciudadanía social.

${ }^{22}$ HOOFT, P. F., Bioética, derechos humanos y sociedad civil. Conceptos introductorios, op. cit. p. 3

23 TOFFLER, A., Entrevista en Revista Muy Interesante, núm. 137, 1992, p. 48.

${ }^{24}$ MARTIN MATEO, R., Tratado de Derecho Ambiental, Trivium, Madrid, 1991, p. 12. 
debe al impulso reflexivo de una serie de científicos como Lovelock que aunque con ciertos excesos esquematizaron proposiciones difícilmente cuestionables como la que afirma que la vida existe únicamente porque las condiciones ambientales de la Tierra son las adecuadas. Este autor y sus colegas llegaron a considerar a la ECÓSFERA (GAIA) como un solo organismo vivo y equiparable al que forman las células para estructurar un sujeto aislado.

José CATOGGIO ${ }^{25}$, prestigioso científico argentino, Director del (CIMA) Centro de Investigaciones del Medio Ambiente de la Facultad de Ciencias Exactas de la Universidad de La Plata, decía en un reportaje que le realizara una revista de publicación industrial, que "el medio ambiente a todo nivel es un problema básicamente de escalas de valores, de filosofía de vida, de ética, de toma de conciencia que trasciende totalmente los costos económicos y las ventajas de lucro o recupero".

LA VISIÓN SOLIDARISTA Y ETICISTA, es según la Suprema Corte de Justicia de la Provincia de Buenos Aires (SCJBA), in re "COPETRO SA"26, fallo del 18/05/98, la actitud que debe asumir la magistratura en defensa del ambiente.

El profesor Eduardo PIGRETTI ${ }^{27}$, enseña que el ETICISMO y la solidaridad, a los que claramente identifica como principios del derecho ambiental, "han sido incorporados en alguna forma al derecho positivo. Así, la Constitución Cuba de 1976, menciona la obligación tanto del Estado", (como de la sociedad), "de proteger la naturaleza y vivir en un ambiente saludable".

La Constitución de la Nación Argentina de 1994, pone en cabeza de todos los habitantes no sólo el derecho ambiental, sino también el deber de preservarlo (art. 41). Y que la Corte Suprema de Justicia de la Nación, in re "Mendoza"28, dijo que, "la tutela del ambiente importa el cumplimiento de los deberes que cada uno de los ciudadanos tienen respecto del cuidado de los ríos, la diversidad de la flora y la fauna, de los suelos colindantes, de la atmósfera. Estos deberes son el correlato que esos mismos ciudadanos tienen a disfrutar de un ambiente sano, para sí y para las generaciones futuras, porque el daño que un individuo causa al bien colectivo se lo está causando a sí mismo".

En la doctrina constitucional, Germán BIDART CAMPOS ${ }^{29}$, desarrolló en ese sentido, un profundo y amplio estudio sobre deberes y obligaciones fundamentales, un capítulo de nuestra doctrina autoral, que parece estar olvidado.

Por ello en el contexto actual de crisis sanitaria y de salud por el COVID 19, los deberes de prevención y cuidado, están en el centro del escenario, lo que fortalece la idea del surgimiento de la "sociedad del cuidado". El cuidado forma parte de los valores humanos

\footnotetext{
${ }^{25}$ CATOGGIO, J., Entrevista en Revista Informe Industrial, Buenos Aires, 1986, p. 46.

${ }^{26}$ SUPREMA CORTE DE JUSTICIA de la Provincia de Buenos Aires, Ac. 60.094, 19/5/98, "Almada, Hugo Néstor c/ Copetro S.A y otro"; Ac. 60.251, "Irazu, Margarita c/ Copetro S.A y otro"; Ac. 60.254, "Klaus, Juan Joaquín c/ Copetro S.A y otro", en LLBA, 1998- 940, con nota laudatoria de STIGLITZ, Gabriel: "Prevención de daños colectivos - en la jurisprudencia de la SCJBA”. Ídem., JA, 1999- I, 227.

27 PIGRETTI, E. A., "Un nuevo ámbito de responsabilidad. Criterios, principios e instituciones de derecho ambiental”, en La responsabilidad por daño ambiental, Centro de Publicaciones Jurídicas y Sociales, 1986, p. 27.

${ }^{28}$ Corte Suprema de Justicia la Nación, M. 1569 XL "Mendoza, Beatriz Silvia y otros c/ Estado Nacional y otros s/ daños y perjuicios (derivados de la contaminación ambiental del Río Matanza Riachuelo)", 20/06/06, Fallos: 326:2316. Para ampliar respecto del contenido de este fallo ejemplar, MORELLO, Augusto M.: "Aperturas y contenciones de la Corte Suprema de Justicia de la Nación", JA, 2006-III, 304.- CAMPS, Carlos: "Derecho procesal ambiental: nuevas pautas de la Corte Suprema de Justicia de la Nación", Revista de Derecho Ambiental 7, Julio / Septiembre 2006, p. 201, Editorial Abeledo- Perrot.- ESAIN, José -GARCIA MINELLA, Gabriela: "Proceso y ambiente: Mucho más que [...] Corte a la contaminación”, Revista de Derecho Ambiental 7, Julio / Septiembre 2006, p. 220. Editorial Abeledo- Perrot.-

${ }^{29}$ BIDART CAMPOS, G. J., Las obligaciones el Derecho Constitucional, Ediar, 1987.
} 
esenciales, y a menudo se sitúa en los márgenes de la sociedad moderna capitalista. Joan $\mathrm{TRONTO}^{30}$, defiende la idea de que el mundo sería muy distinto si ubicáramos al cuidado más cerca del centro de nuestros valores.

Diego GRACIA ${ }^{31}$, expresa que, "de antiguo vienen distinguiéndose dos tipos de deberes, llamados respectivamente, "negativos" y "positivos". Deberes negativos que "son aquellos que dicen lo que no hay que hacer o lo que no se puede hacer. Son prohibiciones. Por eso clásicamente se les ha llamado deberes negativos o de prohibición". Y "los deberes positivos, cuya característica más sobresaliente es que no marcan un límite sino que señalan una tendencia, una dirección".

Por ejemplo, el ser diligente.

Y que la ética y la moral, desde el punto de vista clásico, "debe gestionar lo que antes denominamos deberes positivos, de promoción o de virtud", sin embargo, en la cultura moderna, tanto el Derecho como la Ética y la moral, contienen no sólo deberes negativos o de prohibición, sino también deberes positivos, de promoción o virtudes.

Además, interactúan de manera intensa, en ámbitos específicos, como los que nos convocan en este trabajo. Los límites en el campo de la bioética, entre la moral y el derecho, son difusos, o en todo caso, ambas disciplinas se integran para dar fuerza a una decisión de relevancia jurídica.

Por lo demás, "nos acerca a una dupla central: Bioética y derechos humanos" ${ }^{32}$ en el marco de la sociedad de estas horas. Desgrana conceptos conocidos, zonas grises y, sobre todo, tensiones entre los tres ejes o coordenadas mayores que son compañía constante: Vida, Bioética y dignidad humana. Emerge allí el principio de justicia y un engranaje clave enlaza la Bioética con el Derecho, visto la totalidad como una nueva forma de juridicidad".

Se recuerda que Augusto M. MORELLO ${ }^{33}$, cuando explica el carácter de derecho humano de cuarta generación del Derecho Ambiental, sostiene que existe una suerte de "hipoteca moral" que pesa o grava a las generaciones actuales en beneficio o en tutela de las generaciones futuras: la de dejar el mundo en las mismas condiciones o en mejores condiciones, que las recibidas, como si fuera un legado o herencia futura. Algo así, desde el punto de vista estrictamente jurídico, de una cláusula a favor de un tercero (artículo 504 del Código Civil).

Ricardo LORENZETTI ${ }^{34}$, nos habla de la ética ambiental y de los valores. Y del conflicto moral, enseña que "la tutela del ambiente requiere de decisiones complejas en el plano de los valores. El paradigma ambiental influye en este campo mediante el señalamiento de directivas éticas y morales". Y más adelante apunta que, "el paradigma ambiental es "VALORISTA", es decir establece una orientación a la razón técnica. Y concluye con la

\footnotetext{
30 TRONTO, J., Límites morales: un argumento político para una ética del cuidado, Nueva York, Routledge, 1993. Politóloga, especializada en Estudios de la Mujer. Autora del libro digital ¿Riesgo o cuidado?, publicado por Fundación Medife Edita (fundacionmedife.com.ar/edita).

TRONTO, J., "La Sociedad del cuidado", Noticias, 2020. Disponible en https://noticias.perfil.com/noticias/cultura/la-sociedad-del-cuidado.phtml

${ }^{31}$ GRACIA, D., Prólogo de la obra Bioética, Derecho y Ciudadanía. Casos de bioética en la jurisprudencia, de Pedro Federico HOOFT, Temis, Bogotá ,2005, p. 11.

32 MOREllo, A. M., Presentación de la obra Bioética, Derecho y Ciudadanía. Casos de bioética en la jurisprudencia, de Pedro Federico HOOFT, Temis, Bogotá 2005, p. 16.

${ }^{33}$ MORELlO, A. M., "Los Derechos del Hombre de Tercera y Cuarta Generación”, Estudios de Derecho Procesal. Nuevas Demandas. Nuevas respuestas, vol. 2, Librería Editora Platense 1998, Capítulo LXI, p. 943.

${ }^{34}$ LORENZETTI, R. L., “Teoría del Derecho Ambiental”, La Ley, 2008, p. 20.
} 
siguiente reflexión: "En la actualidad pueden observarse fronteras en campos como la genética, la energía nuclear y el ambiente, en los que se diseñan fuertes límites basados en valores".

También manifiesta que, "la existencia de un valor permite señalar una finalidad a la acción desorientada y puede suministrar un instrumento para apreciar el contenido apropiado o desacertado de las acciones. "En otros casos el valor expresa un juicio comparativo" (compara un valor con otro, mediante "juicios de preferencia o equivalencia"), "es en este aspecto que los "valores ambientales" comienzan a ejercer una función, porque pretenden ser comparados con otros valores y tener prioridad".

Por último, es destacable que, "el ambientalismo introdujo nuevos valores, que han ingresado en los textos constitucionales y supranacionales, y que cumplen la función de límite material para la legislación".

Relacionado con esta cuestión, están los valores fundantes del derecho ambiental, y el fin mismo que lo caracteriza. Siendo un derecho humano de tercera generación, la paz, la solidaridad y la cooperación están en la base de su estructura orgánica. Tratándose además, de un derecho humano de cuarta generación, velar por el interés de las generaciones futuras, y la calidad de vida.

El macro fin del derecho ambiental, es la "sustentabilidad"35 (de la vida, de los ciclos de vida, del equilibrio de los ecosistemas, de los recursos, del desarrollo, de la biodiversidad, la naturaleza, de la flora, de la fauna, del agua).

Hemos mencionado siguiendo al respecto la doctrina de R. LORENZETTI ${ }^{36}$, "el paradigma ambiental", como un modelo de pre comprensión de problemas jurídicos, un cambio profundo o copernicano, no sólo del método del derecho, sino también y lo que resulta más significativo, filosófico o epistemológico, de plantear las cuestiones, analizarlas, examinarlas, verlas, entenderlas, y adoptar las soluciones adecuadas.

Los valores son incorporados con la pretensión de utopía, es decir un lugar al que se puede llegar y da una orientación al ordenamiento. En el campo de la validez material, hay un límite axiológico que puede ser encontrado mediante la invocación de valores.

El diseño de las leyes ambientales es, habitualmente, una proposición de valores a lograr. Por ejemplo, la Ley 25675 General del Ambiente de Argentina, menciona los siguientes valores: gestión sustentable y adecuada del ambiente; la preservación y protección de la diversidad biológica; la implementación del desarrollo sustentable; la preservación, conservación, recuperación y mejoramiento de la calidad de los recursos ambientales, tanto naturales como culturales; la calidad de vida de las generaciones presentes y futuras; la participación social; uso racional y sustentable de los recursos naturales, equilibrio y dinámica de los sistemas ecológicos, conservación de la diversidad biológica.

\section{ENCÍCLICA LAUDATO SI}

La armonía del hombre con la naturaleza, pertenece al acervo moral de las grandes religiones, tanto orientales: budista, hinduista, como las mediterráneas: judeo-cristiana y

\footnotetext{
${ }^{35}$ BENJAMÍN, A. H., “¿Derechos de la naturaleza?”, p. 31, en obra colectiva Obligaciones y contratos en los albores del Siglo XXI, homenaje al Profesor Doctor Roberto LOPEZ CABANA, bajo la Dirección de Oscar AMEAL, y la coordinación de Silvia TANZI, Abeledo-Perrot, 2001. También véase, “Objetivos del Derecho Ambiental”, p. 57, en "El futuro del Control de la Polución y la Implementación Ambiental", Congreso Internacional de Derecho Ambiental 5, Sao Paulo, 2001.

${ }^{36}$ LORENZETTI, R. L., “Teoría del Derecho Ambiental”, La Ley, 2008, p. 1.
} 
mahometana. El Papa Juan Pablo II señaló que "la ecología adquiere una dimensión moral en su origen más allá de consideraciones utilitaristas".

La Encíclica Papal, "Laudato Si', sobre el Cuidado de la Casa Común" (Roma, del 24/05/2015), es un llamado "para entrar en diálogo con todos acerca de nuestra casa común". En palabras del Papa Francisco: "Nuestra casa común es también como una hermana" (nos recordaba San Francisco de Asís). "Esta hermana clama por el daño que le provocamos a causa del uso irresponsable y del abuso de los bienes que Dios ha puesto en ella. Hemos crecido pensando que éramos sus propietarios y dominadores, autorizados a expoliarla" ${ }^{37}$.

"El desafío urgente de proteger nuestra casa común incluye la preocupación de unir a toda la familia humana en la búsqueda de un desarrollo sostenible e integral, pues sabemos que las cosas pueden cambiar". "La humanidad aún posee la capacidad de colaborar para construir nuestra casa común". "Hago una invitación urgente a un nuevo diálogo sobre el modo como estamos construyendo el futuro del planeta. Necesitamos una conversación que nos una a todos, porque el desafío ambiental que vivimos, y sus raíces humanas, nos interesan y nos impactan a todos".

"El movimiento ecológico mundial ya ha recorrido un largo y rico camino, y ha generado numerosas agrupaciones ciudadanas que ayudaron a la concientización. Lamentablemente, muchos esfuerzos para buscar soluciones concretas a la crisis ambiental suelen ser frustrados no sólo por el rechazo de los poderosos, sino también por la falta de interés de los demás" ${ }^{38}$.

Al inicio, hace un breve recorrido de los distintos aspectos de la actual crisis ecológica (lo que está pasando en nuestra casa), la intensificación de ritmos de vida y de trabajo, la velocidad de los cambios que contrasta con la natural lentitud de la evolución biológica. "Después de un tiempo de confianza irracional en el progreso y en la capacidad humana, una parte de la sociedad está entrando en una etapa de mayor conciencia. Se advierte una creciente sensibilidad con respecto al ambiente y al cuidado de la naturaleza, y crece una sincera y dolorosa preocupación por lo que está ocurriendo con nuestro planeta.

Destaca "la contaminación y el cambio climático", y "la cuestión del agua", "problemas íntimamente ligados con la cultura del descarte, que afecta tanto a los seres humanos excluidos como a las cosas que rápidamente se convierten en basura"; además "la exposición a los contaminantes atmosféricos produce un amplio espectro sobre la salud, especialmente de los más pobres, provocando muertes prematuras".

Respecto de la pérdida de biodiversidad, subraya que los recursos de la tierra "están

\footnotetext{
37 "Por eso, entre los pobres más abandonados y maltratados, está nuestra oprimida y devastada tierra, que gime y sufre dolores de parto". "Olvidamos que nosotros mismos somos tierras. Nuestro cuerpo está constituido por los elementos del planeta, su aire es el que nos da aliento y su agua nos vivifica y restaura".

${ }^{38}$ El Santo Padre, manifiesta que, "deseo reconocer, alentar y dar las gracias a todos los que, en los más variados sectores de la actividad humana, están trabajando para garantizar la protección de la casa que compartimos. Merecen una gratitud especial quienes luchan con vigor para resolver las consecuencias dramáticas de la degradación ambiental en las vidas de los más pobres del mundo".
} 
más alto que el beneficio económico que se pueda obtener. En el caso de la pérdida o el daño grave de algunas especies, estamos hablando de valores que exceden todo cálculo".

Luego se refiere al deterioro de la calidad de vida humana y degradación social (el crecimiento desmedido y desordenado de muchas ciudades).

Al referirse a la Inequidad planetaria, afirma que "el ambiente humano y el ambiente natural se degradan juntos, y no podemos afrontar adecuadamente la degradación ambiental si no prestamos atención a causas que tienen que ver con la degradación humana y social. De hecho, el deterioro del ambiente y de la sociedad afectan de un modo especial a los más débiles del planeta" 39 .

También recuerda que "la tierra es esencialmente una herencia común", "El principio de subordinación de la propiedad privada al destino universal de los bienes". Que "la tradición cristiana nunca reconoció como absoluto o intocable el derecho a la propiedad privada y subrayó la función social de cualquier forma de propiedad privada".

El capítulo tercero se detiene en la raíz humana de la crisis ecológica: la encrucijada que nos pone el poderío tecnológico, las olas de cambios en la ciencia, las industrias químicas, medicina moderna, la informática, energía nuclear, el conocimiento del ADN, la revolución digital, la robótica, las biotecnologías, las nanotecnologías, avances y progresos en la tecnociencia, de la humanidad. Las bombas atómicas, el egoísmo y la violencia. La globalización del paradigma tecnocrático.

La crisis y consecuencias del antropocentrismo moderno (la gran desmesura del antropocentrismo), de "relativismo práctico", que "da lugar a un estilo de vida desviado", "lleva a una constante esquizofrenia, que va de la exaltación tecnocrática que no reconoce a los demás seres un valor propio, hasta la reacción de negar todo valor peculiar al ser humano ${ }^{40 "}$.

El Capítulo cuarto lo dedica a la prédica de una ecología integral, ambiental, económica y social, de una ecología cultural, de la vida cotidiana, el principio del bien común, y de la

\footnotetext{
39 "Quisiera advertir que no suele haber conciencia clara de los problemas que afectan particularmente a los excluidos. Ellos son la mayor parte del planeta, miles de millones de personas. Hoy están presentes en los debates políticos y económicos internacionales, pero frecuentemente parece que sus problemas se plantean como un apéndice, como una cuestión que se añade casi por obligación o de manera periférica, si es que no se los considera un mero daño colateral. De hecho, a la hora de la actuación concreta, quedan frecuentemente en el último lugar". "Hoy no podemos dejar de reconocer que un verdadero planteo ecológico se convierte siempre en un planteo social, que debe integrar la justicia en las discusiones sobre el ambiente, para escuchar tanto el clamor de la tierra como el clamor de los pobres". "Mientras tanto, los poderes económicos continúan justificando el actual sistema mundial, donde priman una especulación y una búsqueda de la renta financiera que tienden a ignorar todo contexto y los efectos sobre la dignidad humana y el medio ambiente. Así se manifiesta que la degradación ambiental y la degradación humana y ética están íntimamente unidas".

"Finalmente, reconozcamos que se han desarrollado diversas visiones y líneas de pensamiento acerca de la situación y de las posibles soluciones. En un extremo, algunos sostienen a toda costa el mito del progreso y afirman que los problemas ecológicos se resolverán simplemente con nuevas aplicaciones técnicas, sin consideraciones éticas ni cambios de fondo. En el otro extremo, otros entienden que el ser humano, con cualquiera de sus intervenciones, sólo puede ser una amenaza y perjudicar al ecosistema mundial, por lo cual conviene reducir su presencia en el planeta e impedirle todo tipo de intervención. Entre estos extremos, la reflexión debería identificar posibles escenarios futuros, porque no hay un solo camino de solución. Esto daría lugar a diversos aportes que podrían entrar en diálogo hacia respuestas integrales".

${ }^{40}$ Habla de le necesidad de preservar el trabajo (el valor del trabajo), de la innovación biológica a partir de la investigación (de los organismos genéticamente modificados, sobre cuyo desarrollo, que resulta difícil emitir un juicio general, aunque destaca dificultades importante que derivadas de la introducción de los cereales transgénicos, como la progresiva desaparición de pequeños productores, o la expansión de este cultivos, que arrasa con el complejo entramado de los ecosistemas).
} 
justicia entre generaciones ${ }^{41}$. "Las predicciones catastróficas ya no pueden ser miradas con desprecio e ironía. A las próximas generaciones podríamos dejarles demasiados escombros, desiertos y suciedad. El ritmo de consumo, de desperdicio y de alteración del medio ambiente ha superado las posibilidades del planeta, de tal manera que el estilo de vida actual, por ser insostenible, sólo puede terminar en catástrofes, como de hecho ya está ocurriendo periódicamente en diversas regiones".

"La dificultad para tomar en serio este desafío tiene que ver con un deterioro ético y cultural, que acompaña al deterioro ecológico. El hombre y la mujer del mundo posmoderno corren el riesgo permanente de volverse profundamente individualistas, y muchos problemas sociales se relacionan con el inmediatismo egoísta actual, con las crisis de los lazos familiares y sociales, con las dificultades para el reconocimiento del otro. Muchas veces hay un consumo inmediatista y excesivo de los padres que afecta a los propios hijos, quienes tienen cada vez más dificultades para adquirir una casa propia y fundar una familia".

"Además", continúa diciendo, "nuestra incapacidad para pensar seriamente en las futuras generaciones está ligada a nuestra incapacidad para ampliar los intereses actuales y pensar en quienes quedan excluidos del desarrollo. No imaginemos solamente a los pobres del futuro, basta que recordemos a los pobres de hoy, que tienen pocos años de vida en esta tierra y no pueden seguir esperando. Por eso, « además de la leal solidaridad intergeneracional, se ha de reiterar la urgente necesidad moral de una renovada solidaridad intrageneracional $\gg .{ }^{42}$

LORENZETTI ${ }^{43}$, afirma que esta notable y trascendental Encíclica del Papa Francisco, excede largamente la cuestión ambiental, "para abordar los principales aspectos de lo que numerosos autores presentan como un nuevo ciclo en el sistema del pensamiento", para detenerse en tres aspectos importantes de la misma: 1) la redimensión de la ética de los vulnerables, que comprende no sólo los pobres sino a la propia naturaleza; 2) que estos temas no están en la agenda internacional con el propósito de solucionarlos; y 3) que la solución de estos problemas requieren un cambio en la gobernabilidad global, algo que se viene diciendo reiteradamente en el ambientalismo.

\footnotetext{
41 "La noción de bien común incorpora también a las generaciones futuras. Las crisis económicas internacionales han mostrado con crudeza los efectos dañinos que trae aparejado el desconocimiento de un destino común, del cual no pueden ser excluidos quienes vienen detrás de nosotros. Ya no puede hablarse de desarrollo sostenible sin una solidaridad intergeneracional".
}

${ }^{42}$ Llamativamente, el documento papal incluye en su apartado 186, el principio precautorio.

"En la Declaración de Río de 1992, se sostiene que, « cuando haya peligro de daño grave o irreversible, la falta de certeza científica absoluta no deberá utilizarse como razón para postergar la adopción de medidas eficaces » que impidan la degradación del medio ambiente. Este principio precautorio permite la protección de los más débiles, que disponen de pocos medios para defenderse y para aportar pruebas irrefutables. Si la información objetiva lleva a prever un daño grave e irreversible, aunque no haya una comprobación indiscutible, cualquier proyecto debería detenerse o modificarse. Así se invierte el peso de la prueba, ya que en estos casos hay que aportar una demostración objetiva y contundente de que la actividad propuesta no va a generar daños graves al ambiente o a quienes lo habitan".- Esto no implica oponerse a cualquier innovación tecnológica que permita mejorar la calidad de vida de una población".

"En este contexto, siempre hay que recordar que « la protección ambiental no puede asegurarse sólo en base al cálculo financiero de costos y beneficios. El ambiente es uno de esos bienes que los mecanismos del mercado no son capaces de defender o de promover adecuadamente ". "Cuando se plantean estas cuestiones, algunos reaccionan acusando a los demás de pretender detener irracionalmente el progreso y el desarrollo humano. Pero tenemos que convencernos de que desacelerar un determinado ritmo de producción y de consumo puede dar lugar a otro modo de progreso y desarrollo. Los esfuerzos para un uso sostenible de los recursos naturales no son un gasto inútil, sino una inversión que podrá ofrecer otros beneficios económicos a medio plazo. Si no tenemos estrechez de miras, podemos descubrir que la diversificación de una producción más innovativa y con menor impacto ambiental, puede ser muy rentable".

43 LORENZETTI, R. L., "Los vulnerables", Página 12, 22 de junio de 2015. Disponible en https://www.pagina12.com.ar/diario/sociedad/3-275414-2015-06-22.html 


\section{EL DERECHO AMBIENTAL NO ES UN CONVIDADO DE PIEDRA}

El derecho ambiental, no es indiferente frente a la emergencia, y desde su especialidad, debe tratar de dar explicación a esta problemática, para encontrar respuestas jurídicas adecuadas, a esta gravísima crisis mundial, que demanda un esfuerzo conjunto de todas las ciencias, naturales y sociales, además de una intensa labor de investigación, análisis, proyección y ejecución. En esta batalla, la medicina, las ciencias de la salud, están en estos días, en la más dura trinchera.

Lo primero que debemos dejar en claro es que el derecho ambiental opera en forma conjunta con el derecho de la salud.

Se sabe que existe una íntima relación entre el derecho ambiental y el derecho a la salud (así lo ha señalado en reiteradas oportunidades, Naciones Unidas). En realidad, con el entrañable profesor Augusto M. MORELLO ${ }^{44}$, hace tiempo atrás, advertimos de la integración de la defensa de la salud, por intermedio del ambiente. Asimismo, señalamos en coincidencia con ideas de Germán BIDART CAMPOS ${ }^{45}$, que el derecho a la salud tiene una doble dimensión: derecho a la salud, como derecho individual o subjetivo, y derecho de la salud, que presenta una dimensión de un derecho de incidencia colectiva (interés difuso), y se ubica en la "esfera social" de los individuos, este último tiene una versión pública, cuando es el Estado quien actúa en defensa del mismo.

Desde la especialidad, derecho ambiental, existen instituciones y herramientas que pueden ser útiles en circunstancias tan dramáticas como las actuales.

El instituto de la "emergencia ambiental", que en la Argentina, está previsto en el artículo 2 inc. K) de la ley 25675 General del Ambiente. Además, se lo menciona en el principio de política ambiental, de cooperación del artículo 4, de esta misma ley de presupuesto mínimo de protección ambiental.

Hay una similitud con la emergencia y las catástrofes.

La catástrofes ambientales, tienen tres etapas bien marcadas: 1) temprana, de reducción del riesgo, precautoria o de prevención. 2), de la emergencia en sí misma, que en términos de una epidemia sería cuando el virus estalla o se produce el pico del contagio de la enfermedad, de la mayor propagación de la misma. 3) resiliencia, capacidad de respuesta, adaptación o resistencia post- emergencia.

CHARLES DARWIN, en el "Origen de las especies", enseñaba que "no son los más

de la especie los que sobreviven, ni los más inteligentes. Sobreviven los más flexibles y adaptables a los cambios".

La emergencia ambiental es en realidad, la etapa intermedia de las catástrofes, en este caso, de mayor virulencia del virus, cuando se desata la guerra sin fronteras, cuando las respuestas médicas asistenciales, la prevención o las medidas de reducción o control de la situación amenazante, se desborda.

Estas etapas, están reconocidas en el origen, desarrollo y la investigación. Ejemplo de ello es en la Organización de Naciones Unidas, el MARCO DE Reducción de CATÁSTROFES

\footnotetext{
${ }^{44}$ MOREllo, A. M. y CAFFERATTA, N. A., "Dimensión social del Derecho de la Salud. Problemas, enfoques y perspectivas", en El Derecho, t. 213, 2005, pp. 937-944.

45 BIDART CAMPOS, G. J., "La dimensión de la salud como bien colectivo y los servicios de salud". La Ley, núm. 2001-F, 906. Para ampliar ver MOSSET ITURRASPE, J., "Daño a la salud”, La Ley, núm. 2011-A, 1079.
} 
de SENDAI. En el prefacio de dicho documento internacional, se dice que: "el MARCO DE SENDAI es el instrumento sucesor del Marco de Acción de HYOGO para 2005-2015: Aumento de la resiliencia de las naciones y las comunidades ante los desastres".

\section{LA LÓGICA DE LA PRECAUCIÓN}

La contaminación ambiental, producida por la presencia del virus, en la medida que genera daño ambiental colectivo, puede ser combatida por herramientas esencialmente preventivas provenientes de la especialidad.

Todo el instrumental ambiental concurre y resulta de aplicación en cuestiones de este tipo cuando es necesario prevenir, evitar que el riesgo se transforme en un peligro efectivo de daño grave o irreversible, aun en situaciones de incertidumbre científica (absoluta o inequívoca) o ausencia de información, conforme la fórmula habitual del principio precautorio, más aun en situaciones de amenaza cierta, en aplicación del principio de prevención, según lo establece el artículo $4^{\circ}$ ley 25675 General del Ambiente Argentina.

Ricardo LORENZETTI, apunta que en esta pandemia, las medidas que se adoptan siguen la "lógica de la precaución", porque no se sabe la causa de la infección, ni del contagio, ni tampoco se conoce la etiología del virus, es decir no existe certeza científica en absoluto.

Paradójicamente, en el siglo XXI, la contención del contagio o propagación de la pandemia, se viene combatiendo con "herramientas de la Edad Media: la cuarentena" (Lorenzetti), el aislamiento social. Es lo único cierto que tenemos, el contacto social masivo, es inconveniente en esta situación.

En ese sentido, se destaca que la ley 26994, el Código Civil y Comercial de Argentina (2015), contiene una serie de reglas novedosas, en especial los artículos 10, 14, abuso del derecho ambiental (ECO- ABUSO, según lo bautizó Gonzalo SOZZO ${ }^{46}$ ), el artículo 240, de socialización del ejercicio de los derechos individuales (deber de compatibilización), 1710 y concordantes, en materia del deber de prevención, 1757 (actividades riesgosas o peligrosas) que resultan de plena aplicación en diversos supuestos de esta probable propagación de la pandemia.

Asimismo, siendo el origen de la enfermedad un virus es de aplicación a los fines del acceso a la información científica a niveles internacionales, asistencia técnica y financiera, en relación a los recursos genéticos, animales y microorganismos, el Convenio de Diversidad Biológica (CDIB) y el Protocolo de Nagoya (PN).

\section{COLOFÓN}

Hemos estudiado, con Enrique PERETTI, esta cuestión antes que ahora, desde el punto de vista ambiental, en una obra conjunta ${ }^{47}$, donde proponemos el análisis de la evolución del derecho ambiental a escala global, partiendo de dos pilares fundantes: la solidaridad y la sustentabilidad.

En efecto para entender el presente y el futuro del derecho ambiental, no puede prescindirse de la consideración de la crisis de la teoría filosófica cartesiana donde se modeló y

\footnotetext{
${ }^{46}$ SOZZO, G., "El giro ecológico del abuso del derecho", Revista de Derecho Ambiental, núm. 51-1. Para ampliar ver del mismo autor, Derecho Privado Ambiental. El giro ecológico del derecho privado. Rubinzal, septiembre de 2019.

47 CAFFERATTA, N. A. y PERETTI, E., Los nuevos desafíos del derecho ambiental, con prólogo de Ricardo LORENZETTI, Rubinzal Culzoni, 2019.
} 
se sustentó el derecho positivo moderno, caracterizada por un marcado acento antropocéntrico, y del avance actual hacia una visión cada día más ECOCÉNTRICA, que plantea una nueva interpretación de la relación del Hombre con la Naturaleza (de la que da cuenta, el artículo 240 del CCYC), rompiendo la hegemonía de la idea del dualismo ontológico, para comprender al ser humano como parte de la naturaleza que interactúa en un modo sistémico de interrelación permanente y dinámico con los demás seres vivos, conformando una cosmogénesis que comparte no solo su origen sino también su destino (LEONARDO BOFF, en Argentina, YOLANDA ORTIZ).

Esta situación trae aparejada una necesidad de repensar la condición de los "sujetos de derecho" en el ámbito del derecho ambiental, donde no sólo emerge con claridad, en ámbitos normativos, del Constitucionalismo Andino, Ecuador y Bolivia, doctrinario y jurisprudenciales, la idea de reconocer a la "naturaleza" sino como un bien colectivo o común protegido (artículo 14 del CCYC, Gonzalo SOZZO) ${ }^{48}$, como un sujeto de derecho (toda vez que desde la óptica del "paradigma ambiental", se concibe a la naturaleza como sujeto de derecho), sino además plantea una nueva valoración jurídica del "otro" imponiéndose un ensanchamiento del alcance conceptual de la alteridad (Federico DE LORENZO ${ }^{49}$ ), comprensivo no solo de los demás seres humanos, sino extendiendo el mismo a otros seres vivos, a los bienes ambientales, e incluso a las generaciones futuras.

Aquella visión jurídica globalizada, es la que lleva a una corriente de opinión altamente representativa, a sostener que "parece evidente que caminamos acelerada e inexorablemente hacia la creación de un espacio jurídico transnacional que precisará de un derecho "a medida" alejado de los patrones clásicos. Un derecho transnacional que, al trascender el derecho internacional convencional, imponga reglas a Estados, corporaciones e individuos a las que no puedan oponerse intereses individuales o nacionales". ${ }^{50}$

Esta problemática aún no resuelta, juega en contra de la mayor efectividad de las medidas que se deben adoptar para superar esta pandemia (COVID 19), de característica mundial, y que alcanza una afectación de calamidad o estrago público; por ello, no dejamos de recordar la frase brillante del profesor Isidoro GOLDENBERG ${ }^{51}$, quien fuera profesor emérito de la Facultad de Derecho de la Universidad Nacional de Buenos Aires, advertía proféticamente, que el ser humano, paradójicamente, es la primera especie inteligente del mundo y la primera que por su propia conducta, está en peligro de extinción.

\section{REFERENCIAS BIBLIOGRÁFICAS}

- ALCONADA MON, H., "Yuval Noah Harari: 'La falta de solidaridad global y de liderazgo representa un peligro inmenso para la humanidad"”, La Nación, 5 de abril de 2020. Disponible en https://www.lanacion.com.ar/el-mundo/yuval-noah-harari-la-falta-desolidaridad-global-y-de-liderazgo-representa-un-peligro-inmenso-para-la-humanidad$\underline{\text { nid2350906 }}$

\footnotetext{
${ }^{48} \mathrm{SOZZO}$, G., "Proteger los bienes comunes como función del Derecho privado. La necesidad de herramientas que incluyan las acciones de clase". La Ley, 2018, p. 1.

49 DE LORENZO, M. F., "Repensar al "otro": reflexiones sobre el derecho civil" Revista Responsabilidad Civil y Seguros, núm. 2019-VI, 3, 2019.

${ }^{50}$ REAL FERRER, G., "Sostenibilidad, Transnacionalidad y Transformación del Derecho", en Revista de Derecho Ambiental, núm. 32 -octubre/ diciembre, Buenos Aires, p. 75.

${ }^{51}$ GOLDENBERG, I. H., "Reflexiones acerca del futuro del hombre en la sociedad tecnológica" en Crítica de Legislación y Jurisprudencia, , año IV, núm. 8, 1972. GOLDENBERG, I. H. y CAFFERATTA, N. A., Daño ambiental: problemática de su determinación causal, ABELEDO- PERROT, Buenos Aires, 2001.
} 
- $\quad$ ALCONADA MON, H., "Frank Snowden: 'Las epidemias son como mirarse al espejo de la humanidad, y puedo decir que no todo es bello", La Nación, 29 de marzo de 2020. Disponible en https://www.lanacion.com.ar/el-mundo/frank-snowden-las-epidemias-soncomo-mirarse-al-espejo-de-la-humanidad-y-puedo-decir-que-no-todo-es-bello-nid2348455

- BENJAMÍN, A. H., “¿Derechos de la naturaleza?”, p. 31, en obra colectiva Obligaciones y contratos en los albores del Siglo XXI, homenaje al Profesor Doctor Roberto LOPEZ CABANA, bajo la Dirección de Oscar AMEAL, y la coordinación de Silvia TANZI, Abeledo-Perrot, 2001.

- BIDART CAMPOS, G. J., "La dimensión de la salud como bien colectivo y los servicios de salud". La Ley, núm. 2001-F, 906.

- $\quad$ BIDART CAMPOS, G. J., Las obligaciones el Derecho Constitucional, Ediar, 1987.

- BOFF, L., Sustentabilidad. La urgencia ante el grito de la tierra, Editorial Santa María, Buenos Aires, 2017, p. 37.

- BRAÑES, R., "E1 Derecho para el Desarrollo Sostenible en la América Latina de nuestros días", Revista de Derecho Ambiental, publicación del Centro de Derecho Ambiental Facultad de Derecho Universidad de Chile, Año II, N. ${ }^{\circ}$ 2, 2006, p. 17.

- BRAÑES, R., Manual de Derecho Ambiental mexicano, FCE, México, 2004.

- BRAÑES, R., "El Derecho Ambiental en América Latina", en GONZÁLEZ LAXE, F. (Aut.), Actas del IV Congreso Nacional de Derecho Ambiental, Aranzadi Thomson Reuters, Madrid, 2002, p. 73-148.

- BRAÑES, R., "Tres décadas de evolución del derecho ambiental y su aplicación en América Latina”, p. 94 en Primeras Jornadas Nacionales de Derecho Ambiental / 28 y 29 de Noviembre de 2001, Comisión Nacional del Medio Ambiente y Centro de Derecho Ambiental de la Facultad de Derecho de la Universidad de Chile.

- BRAÑES, R., El desarrollo del derecho ambiental latinoamericano y su aplicación, PNUMA, 2001.

- CAFFERATTA, N. A. y PERETTI, E., Los nuevos desafios del derecho ambiental, con prólogo de Ricardo LORENZETTI, Rubinzal Culzoni, 2019.

- CAfFeratta, N. A y PERETti, E., Pandemia de coronavirus. El dramático desafío global de la humanidad, en Rubinzal.

- CAFFeratta, N. A, PERETTI, E y LOREnZETTI, P., "El aporte del Derecho Ambiental a la lucha contra el Coronavirus (Covid-19)", Rubinzal, Buenos Aires.

- CAMPS, C., "Derecho procesal ambiental: nuevas pautas de la Corte Suprema de Justicia de la Nación", Revista de Derecho Ambiental, núm. 7, 2006, p. 201.

- CATOGgiO, J., Entrevista en Revista Informe Industrial, Buenos Aires, 1986, p. 46.

- Corte Suprema de Justicia la Nación, M. 1569 XL "Mendoza, Beatriz Silvia y otros c/ Estado Nacional y otros s/ daños y perjuicios (derivados de la contaminación ambiental del Río Matanza Riachuelo)", 20/06/06, Fallos: 326:2316.

- CSJ 140/2011 (47-B)/ CS1.ORIGINARIO "BARRICK Exploraciones Argentinas S.A y otro c/ Estado Nacional s/ acción declarativa de inconstitucionalidad". 04.07.2019. Fallos 342:917. CSJ 000714/2016/RH001 MAJUL, JULIO JESUS c/ MUNICIPALIDAD DE PUEBLO GENERAL BELGRANO Y OTROS S/ACCION DE AMPARO AMBIENTAL $11 / 07 / 2019$. 
- CSJ 1531/2017/CS1. Cuestión de Competencia. 22.08.2019. "FERNÁNDEZ, Miguel Ángel s/ infracción ley 24.051".

- CSJ. La Pampa, Provincia de cl. Mendoza, Provincia de s/ uso de aguas. CSJ 243/2014 (50L) ICS1 ORIGINARIO (01/12/2017) Fallos: 340:1695.

- DE LORENZO, M, F., "Repensar al "otro": reflexiones sobre el derecho civil" Revista Responsabilidad Civil y Seguros, núm. 2019-VI, 3, 2019.

- EDITORIAL, "La destrucción del ecosistema y el origen del coronavirus", La Nación, 5 de abril de 2020. Disponible en https://www.lanacion.com.ar/editoriales/la-destruccion-delecosistema-y-el-origen-del-coronavirus-nid2350879

- GARCÍA JAÉN, B., "Entrevista a Luigi Ferrajoli, filósofo: 'Los países de la UE van cada uno por su lado defendiendo una soberanía insensata", El País, 28 de marzo de 2020. Disponible en https://elpais.com/ideas/2020-03-27/luigi-ferrajoli-filosofo-los-paises-de-laue-van-cada-uno-por-su-lado-defendiendo-una-soberania-insensata.html

- GARCíA Minella, G., "Proceso y ambiente: Mucho más que [...] Corte a la contaminación", Revista de Derecho Ambiental, núm. 7, 2006, p. 220.

- GOldenberG, I. H. y CAFFERATTA, N. A., Daño ambiental: problemática de su determinación causal, ABELEDO- PERROT, Buenos Aires, 2001.

- GOLDENBERG, I, H,. "Reflexiones acerca del futuro del hombre en la sociedad tecnológica" en Crítica de Legislación y Jurisprudencia, , año IV, núm. 8, 1972.

- GRACIA, D., "Prólogo" en HOOFT, P.F., Bioética, Derecho y Ciudadanía. Casos de bioética en la jurisprudencia, Temis, Bogotá, 2005, p. 11.

- HOOFT, PEDRO F., Bioética, derechos humanos y sociedad civil, Temis, Bogotá, 2005, p. 3.

- LORENZETTI, P., "El Derecho Ambiental en tiempos de pandemia", La Opinión, edición digital, 2020.

- LORENZETTI, R., “El desafío moral de la pandemia”, en www.infobae.com, 2020.

- LORENZETTI, R., "La salud humana y la salud de la naturaleza", en www.infobae.com, 2020.

- LORENZETTI, R., "Medidas ante la pandemia y el Estado de Derecho", en www.infobae.com, 2020.

- LOREnZETTI, R., "Pandemia: la salida del aislamiento y sus desafíos", en www.infobae.com, 2020.

- LORENZETTI, R. L., "Los vulnerables", Página 12, 22 de junio de 2015. Disponible en https://www.pagina12.com.ar/diario/sociedad/3-275414-2015-06-22.html

- LORENZETTI, R. L., “Teoría del Derecho Ambiental”, La Ley, 2008, p. 1.

- MARTÍN MATEO, R., El hombre: una especie en peligro, Campomanes S.L., 1993, pp. 19- 24, pp. 83- 107.

- $\quad$ Martin MATEO, R., Tratado de Derecho Ambiental, Trivium, Madrid, 1991, p. 12.

- MOREllo, A, M., "Aperturas y contenciones de la Corte Suprema de Justicia de la Nación”, JA, núm. 2006-III, p.304. 
- MOREllo, A. M. y CAFFERATtA, N. A., "Dimensión social del Derecho de la Salud. Problemas, enfoques y perspectivas", en El Derecho, t. 213, 2005, p. 937-944.

- Morello, A. M., Presentación de la obra Bioética, Derecho y Ciudadanía. Casos de bioética en la jurisprudencia, de Pedro Federico HOOFT, Temis, Bogotá ,2005, p. 16

- MORELlO, A. M., "Los Derechos del Hombre de Tercera y Cuarta Generación", Estudios de Derecho Procesal. Nuevas Demandas. Nuevas respuestas, vol. 2, Librería Editora Platense 1998, Capítulo LXI, p. 943.

- MOSSET ITURRASPE, J., "Daño a la salud”, La Ley, núm. 2011-A, 1079.

- PIGRETTI, EDUARDO A., "Un nuevo ámbito de responsabilidad. Criterios, principios e instituciones de derecho ambiental", en La responsabilidad por daño ambiental, Centro de Publicaciones Jurídicas y Sociales, 1986, p. 27.

- REAL FERRER, G., "Sostenibilidad, Transnacionalidad y Transformación del Derecho", en Revista de Derecho Ambiental, núm. 32, Buenos Aires, p. 75.

- ROBINSON, N. A y WALZER, C., "How do we prevent the next Outbreak", Scientific American, 2020.

- ROBINSON, N., "One World on Health, Legal preparations to avert a Pandemic", Westchester Lawyer, marzo 2020.

- SOZZO, G., "El giro ecológico del abuso del derecho", Revista de Derecho Ambiental, núm. 51-1.

- SOZZO, G., "Proteger los bienes comunes como función del Derecho privado. La necesidad de herramientas que incluyan las acciones de clase". La Ley, 2018, p. 1.

- SOZZO, G., Derecho Privado Ambiental. El giro ecológico del derecho privado. Rubinzal, 2019.

- SUPREMA CORTE DE JUSTICIA de la Provincia de Buenos Aires, Ac. 60.094, 19/5/98, "Almada, Hugo Néstor c/ Copetro S.A y otro"; Ac. 60.251, "Irazu, Margarita c/ Copetro S.A y otro"; Ac. 60.254, "Klaus, Juan Joaquín c/ Copetro S.A y otro", en LLBA, 1998- 940, con nota laudatoria de STIGLITZ, Gabriel: "Prevención de daños colectivos - en la jurisprudencia de la SCJBA”. Ídem., JA, 1999- I, 227.

- $\quad$ TOFFlER, A., Entrevista en Revista Muy Interesante, núm. 137, 1992, p. 48.

- TRONTO, J., "La Sociedad del cuidado", Noticias, 2020. Disponible en https://noticias.perfil.com/noticias/cultura/la-sociedad-del-cuidado.phtml

- TRONTO, J., Límites morales: un argumento político para una ética del cuidado, Nueva York, Routledge, 1993. 